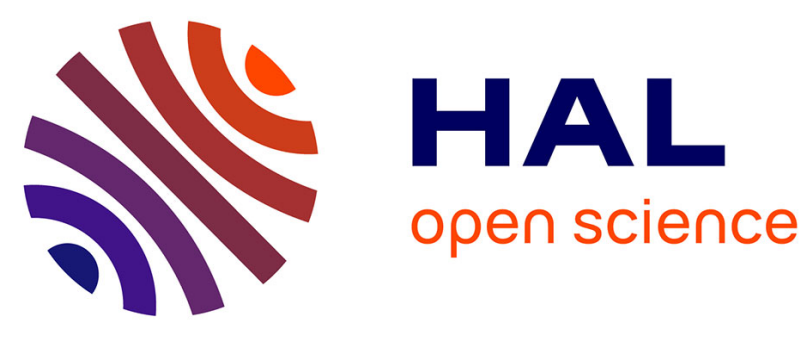

\title{
Graphite target for the spiral project
}

\author{
J.C. Putaux, Pierre Bertrand, M. Ducourtieux, A. Ferro, P. Foury, O. \\ Kaitasov, L. Kotfila, N. Lecesne, R. Leroy, C.F. Liang, et al.
}

\section{To cite this version:}

J.C. Putaux, Pierre Bertrand, M. Ducourtieux, A. Ferro, P. Foury, et al.. Graphite target for the spiral project. International Conference on Electromagnetic Isotope Separators and Techniques Related to their Applications 13 Emis-13 Electromagnetic Isotope Separators and Techniques Related to their Applications 13, Sep 1996, Bad Durkheim, Germany. pp.113-116, 10.1016/S0168-583X(96)01022-1 . in2p3-00012983

\section{HAL Id: in2p3-00012983 https://hal.in2p3.fr/in2p3-00012983}

Submitted on 27 Oct 2017

HAL is a multi-disciplinary open access archive for the deposit and dissemination of scientific research documents, whether they are published or not. The documents may come from teaching and research institutions in France or abroad, or from public or private research centers.
L'archive ouverte pluridisciplinaire HAL, est destinée au dépôt et à la diffusion de documents scientifiques de niveau recherche, publiés ou non, émanant des établissements d'enseignement et de recherche français ou étrangers, des laboratoires publics ou privés. 
CERN LIBRARIES, GENEVA

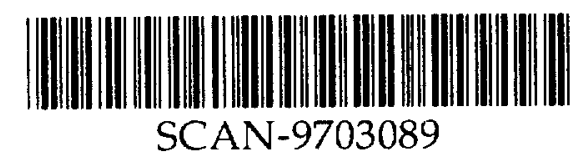

\section{GRAPHITE TARGET FOR THE SPIRAL PROJECT}

J.C.Putaux ${ }^{1}$.P.Bertrand ${ }^{3}$. M.Ducourtieux ${ }^{1}$. A.Ferro ${ }^{1}$, P.Foury ${ }^{1}$. O.Kaitasov ${ }^{2}$. L.Kotfila $^{1}$. N.Lecesne ${ }^{3}$, R.Leroy ${ }^{3}$, C.F.Liang ${ }^{2}$, M.Loiselet ${ }^{4}$, J.Mandin ${ }^{3}$, L.Maunoury ${ }^{3}$, A.C.Mueller ${ }^{1}$, J.Obert ${ }^{1}$, J.Y.Pacquet ${ }^{3}$, N.Pauwels ${ }^{1}$. J.C.Potier ${ }^{1}$, J.Proust ${ }^{1}$, E.Robert ${ }^{3}$, M.O.Ruault ${ }^{2}$, G.Ryckewaert ${ }^{4}$, P.Sortais ${ }^{3}$. M.Toulemonde ${ }^{3}$, A.C.C.Villari ${ }^{3}$.

1. IPN, 91406 Orsay cédex, France

2. CSNSM, Bat.104-108, 91406 Orsay cédex, France

3. GANIL, BP 5027, 14021 Caen cédex, France

4. CRC-IPN, UCL, B-1348 Louvain-La-Neuve, Belgium

IPNO 9603

Presented at the thirteenth International Conference EMIS 13

Bad Durkheim, Germany, September 23-27, 1996 


\title{
GRAPHITE TARGET FOR THE SPIRAL PROJECT
}

\author{
J.C.Putaux ${ }^{1}$, P.Bertrand ${ }^{3}$. M.Ducourtieux ${ }^{1}$, A.Ferro', P.Foury', O.Kaitasov ${ }^{2}$, \\ L.Kotfila $^{1}$, N.Lecesne ${ }^{3}$, R.Leroy ${ }^{3}$, C.F.Liang ${ }^{2}$, M.Loiselet ${ }^{4}$, J.Mandin ${ }^{3}$, L.Maunoury ${ }^{3}$, \\ A.C.Mueller ${ }^{1}$, J.Obert ${ }^{1}$, J.Y.Pacquet ${ }^{3}$, N.Pauwels ${ }^{1}$, J.C.Potier ${ }^{1}$, J.Proust ${ }^{1}$, E.Robert ${ }^{3}$, \\ M.O.Ruault ${ }^{2}$, G.Ryckewaert ${ }^{4}$, P.Sortais ${ }^{3}$, M.Toulemonde ${ }^{3}$, A.C.C.Villari ${ }^{3}$ \\ I.IPN, 91406 Orsay cédex, France \\ 2.CSNSM, Bat. 104-108, 91406 Orsay cédex, France \\ 3.GANIL, BP 5027, 14021 Caen cédex, France \\ 4.CRC-IPN, Universite Cath. de Louvain, B-1348 Louvain-La-Neuve, Belgium
}

\begin{abstract}
We present here a study of the thermal and physical properties of graphite targets for the SPIRAL project. The main objective was to develop an optimized set-up both mechanically and thermally resistant, presenting good release properties (hot targets with thin slices). We show here the results of irradiation tests concerning the mechanical and thermal resistance of the first prototype of SPIRAL target with conical geometry. We also study the micro-structural properties of the graphite target in order to check that the release properties are not deteriorated by the irradiation. Finally, we present the results concerning the latest pilot target internally heated by an electrical current. This setup has been especially designed to be used in case of low power primary beams.
\end{abstract}

\section{Introduction}

One of the main problems for the SPIRAL project, is that the target should be able to absorb the $6 \mathrm{~kW}$ of primary heavy-ion beam while conserving a fast release of the radioactive isotopes. The aim of this paper is to present a target which is optimized mechanically and thermally for the use with heavy-ion beams.

In the first part of this paper we explain the damage observed in the target used for the initial tests of production at GANIL [1].

The second part will be devoted to new target designs taking into account the results of test and simulation of thermal exchanges in classical cylindrical targets.

In the third part we study the evaporation rate of graphite under vacuum in order to estimate the maximum temperature allowed in a SPIRAL target working more than 15 days at high temperature.

Then, in the 4th part, we present results of a TEM (Transmission Electronic Microscopy) study concerning the micro-structural properties of the target material.

Finally, we outline a set-up we developed which can work with a varying range of powers beams. It is composed of a conical target internally heated by an electric current.

\section{First experiments}

The beam from the GANIL cyclotrons bombarded a carbon target mounted in a thin tantalum tube with a $25 \mu \mathrm{m}$ thick tantalum entrance window. This system was connected to an ECR ion source by a tantalum transfert tube $60 \mathrm{~cm}$ long. 
The graphite thick target was chosen for its refractory properties, excellent release characteristics (low grain size $4 \mu \mathrm{m}$ and reasonable open porosity $8 \%[2,3]$ ) and low $\mathrm{Z}$, which provides a higher yield via projectile fragmentation. The graphite was supplied by Le Carbone Lorraine (grade 2318) and the target was composed of 25 parallel slices (diameter $20 \mathrm{~mm}$, thickness $0.7 \mathrm{~mm}$ ) separated by $1 \mathrm{~mm}$. The target was heated via radiation transfer from an ohmically heated container kept in the temperature range of $1500^{\circ} \mathrm{C}$ $2000^{\circ} \mathrm{C}$.

Two equivalent targets were irradiated using two different primary heavy-ion beams. The beams used for the tests were ${ }^{20} \mathrm{Ne}(95 \mathrm{AMeV}, 200$ particle $\mathrm{nA})$ during 48 hours and ${ }^{78} \mathrm{Kr}(73 \mathrm{AMeV}, 35$ particle $\mathrm{nA})$ during 24 hours. The targets were inspected after the irradiations. In the case of the ${ }^{78} \mathrm{Kr}$ beam, the target and the container were found to be intact. However, in the case of the ${ }^{20} \mathrm{Ne}$ beam, a hole with a double cone profile from the 8 th to the 20 th slice and with a maximum size at the 13 th slice was found. The carbon evaporated from the target was found at the container surface as $\mathrm{TaC}$.

The hole experimentally observed with the ${ }^{20} \mathrm{Ne}$ beam is due to a localized heating of the target by the heavy-ion beam. At high temperature part of the carbon can either slightly evaporate or instantaneously sublimate at $3000^{\circ} \mathrm{C}$.

The following scenario could be imagined : in the regions where the heavy-ion beam is the most intense, a small hole begins to appear due to the evaporation or sublimation of the graphite. The hole formed is conical : its diameter increases when one approaches the 13 th slice, corresponding to the expected location of the Bragg peak. The beam can, therefore, pass through the damaged slices and bombard the next ones previously preserved. The following slices can be holed in turn. Indeed, as each following holed slice intercepts part of the beam, the Bragg peak is distributed over several slices and the power deposited is progressively diminished. The diameter of the hole decreases also progressively, up to the point where the power deposited is sufficiently small in order to keep intact the target slice. This process depends basically of the power density as well as the evaporation rate.

\section{New target design}

We have developed a target with a conical profile which provides for a distribution of the power deposited in the Bragg peak over a much greater depth in the target. The target system (fig1) consists of a conical target (angle $45^{\circ}$ ) with 30 graphite slices (diameter $3 \mathrm{~mm}$ to $40 \mathrm{~mm}$; thickness $0.7 \mathrm{~mm}$; separated by $1.3 \mathrm{~mm}$ ), in a radiating graphite container and placed in a cooled aluminium enclosure. The major way for the thermal exchanges between the target, the container and the enclosure took place was grey body radiation, as there was almost no contact between these various parts. In order to test this new target design, we performed experiments at the Louvain-La-Neuve (Belgium) cyclotron which can deliver a $30 \mathrm{MeV}$ proton beam up to $6 \mathrm{~kW}$. The advantage of these experiments is that the power deposited by the $30 \mathrm{MeV}$ proton beam in the conical graphite target is very similar to that deposited by a ${ }^{20} \mathrm{Ne}$ beam of $95 \mathrm{AMeV}$ [4].

The simulation has shown that a target with a conical shape can be heated by the $6 \mathrm{~kW}$ beam without an external heat source and presents a uniform temperature profile. On-line tests performed during 5 hours with increasing power up to $6 \mathrm{~kW}$, validated this new design and demonstrated that we can achieve about $1700^{\circ} \mathrm{C}$ providing good release properties. The target was examined afterwards and it was found to be intact : no hole or other damage. 


\section{Evaporation rate of the graphite}

We have studied the thermal resistance of the target to ensure that under vacuum, it will sustain the beam's heating for the 15 days of a SPIRAL cycle.

Knowledge of the rate of evaporation of graphite in relation to temperature is therefore an essential parameter to determine target lifetime. This parameter depends enormously on the type of graphite used (size of grains, density, open porosity) as well as the nature of the residual gases. This led us to carry out our own measurement of graphite evaporation for the graphite we use.

We heated by Joule effect several graphite samples (Le Carbone Lorraine 2318) to temperatures between $2100^{\circ} \mathrm{C}$ and $2400^{\circ} \mathrm{C}$ for pre-determined amounts of time according to the temperature. The samples were enclosed in a graphite tube and under vacuum ( $7.10^{-6} \mathrm{mbar}$ ). The temperature was measured by an optical pyrometer.

The graphite samples were $5 \mathrm{~mm}$ in diameter and $20 \mathrm{~mm}$ long. The evaporation rate was determined by measuring the reduction in diameter size.

The results in figure (2) are compared with the literature [5], they match within a factor of 2. This means that in spite of its particular micro-structure, the graphite 2318 is as heat resistant as graphites of higher density cited in the literature.

In light of the results, we can ascertain that the limiting operative temperature is $2100^{\circ} \mathrm{C}$, above which, by the end of two weeks, more than $5 \%$ of a $40 \mathrm{~mm}$ diameter target will be evaporated.

\section{Graphite microstructure stability at high temperature}

In order to optimise the diffusion of radio-elements produced in the target by means of heavy ions the target has to be hot and thin.

For ceramic materials such as graphite, the pertinent parameter for the diffusion is not only the thickness, but the size of the monocrystal grains and the open porosity. Intragrain diffusion is slower than diffusion through surface and boundary grain.

Experiments on different types of ceramic materials have confirmed these facts [3] It is important to check that the modification of micro-structural characteristics, particularly the heating due to the beam interaction, does not deteriorate the diffusion properties. This is why we have performed TEM measurements to study the influence of heating and ion attacks on the structure of the graphite we used (Le Carbone Lorraine 2318). We studied 2 samples : one unheated and the other having been heated to $2500^{\circ} \mathrm{C}$ under vacuum for several days.

For TEM, very thin (thickness $<1000$ angstrom) samples are required. To obtain such a thickness, we have mechanically polished our samples until a thickness of $50 \mu \mathrm{m}$, then we proceeded to argon ion etch $(5 \mathrm{KV}, 0.5 \mathrm{~mA})$. A priori this type of etching does not damage a lot the grains.

This TEM observation shows that there are 3 distinct zones. The first one is made up of extremely small crystallites (diameter $<0.01 \mu \mathrm{m}$ ) totally disoriented in relation to one another. Another zone is composed of large precipitates (diameter $<0.5 \mu \mathrm{m}$ ) We also see a zone which spreads over several microns (about $4 \mu \mathrm{m}$ ) and made up of crystallites $(0.03$ $\mu \mathrm{m} \times 0.5 \mu \mathrm{m}$ ) piled up. This last zone corresponds to the initial grain used as raw material before graphitization. These grains are not monocrystallin entities, but arrangements of crystallites. 
The results for the heated sample were similar to those of the unheated sample. We observed no notable evolution of the micro-structures. This means that, a priori, the diffusion properties of the target are not deteriorated by the beam heating.

Moreover, we think that irradiation with heavy ions creates important defects similar to those caused by ion etching carried out during the preparation of the samples for the electron microscope; however part of these effects could even lead to improved diffusion.

\section{Conical graphite target with auxilary heating}

Typically the adequate working temperature for the target is $1500^{\circ} \mathrm{C}-2000^{\circ} \mathrm{C}$. With a $6 \mathrm{~kW}$ beam on a conical graphite target, we have shown, through digital simulation followed by on-line tests at the Louvain-La-Neuve cyclotron, that the target was selfheated by the beam to $1800^{\circ} \mathrm{C}$. In the case of primary beam powers lower than $6 \mathrm{~kW}$ (e.g. during the 96-97 test at GANIL we use $400 \mathrm{~W}$ ), the target will not be hot enough and auxilary heating will be required.

We have designed and tested a setup where the conical target is directly heated by a current along the length of the central axis of the target.

Figure (3) shows the temperature profile of the conical target and the container for different electric power currents.

After three tests of several hours at about $2 \mathrm{~kW}$, it seems that the target did not suffer from any significant evaporation.

\section{Conclusion and future developments}

We have made a pilot target for the first test runs of SPIRAL (fig 4,5)

In November 1996 at SIRa in GANIL (France), we will test on-line the same pilot target, but of a smaller size to take into account the lower power beam $(400 \mathrm{~W})$ that we will be using.

At the beginning of 1997, we hope to have an opportunity to test at Louvain-LaNeuve the thermal performance of a normal size pilot target on their proton beam with a range of powers and keeping the target at proper working temperature by ohmic heating.

\section{References}

[1] A.C.C. Villari et al, Nucl. Phys. A588, 267c (1995).

[2] Le Carbone-Lorraine, Technical specifications (1994).

[3] R. Kirchner, Nucl. Instr. Meth. Phys. Res. B70, 186 (1992).

[4] P. Foury et al, Thermal dynamic studies of ISOL targets, to be published.

[5] E.N. Marmer, High temperature materials, Freund Publishing House (Israel) (1971). 


\section{Figure captions}

Figure 1 : Schematic representation of the conical target.

Figure 2 : Rate of evaporation of graphite.

Figure 3 : Target temperature profile versus electrical heating power.

Figure 4 : Conical graphite target.

Figure 5 : Target set-up for SPIRAL. 


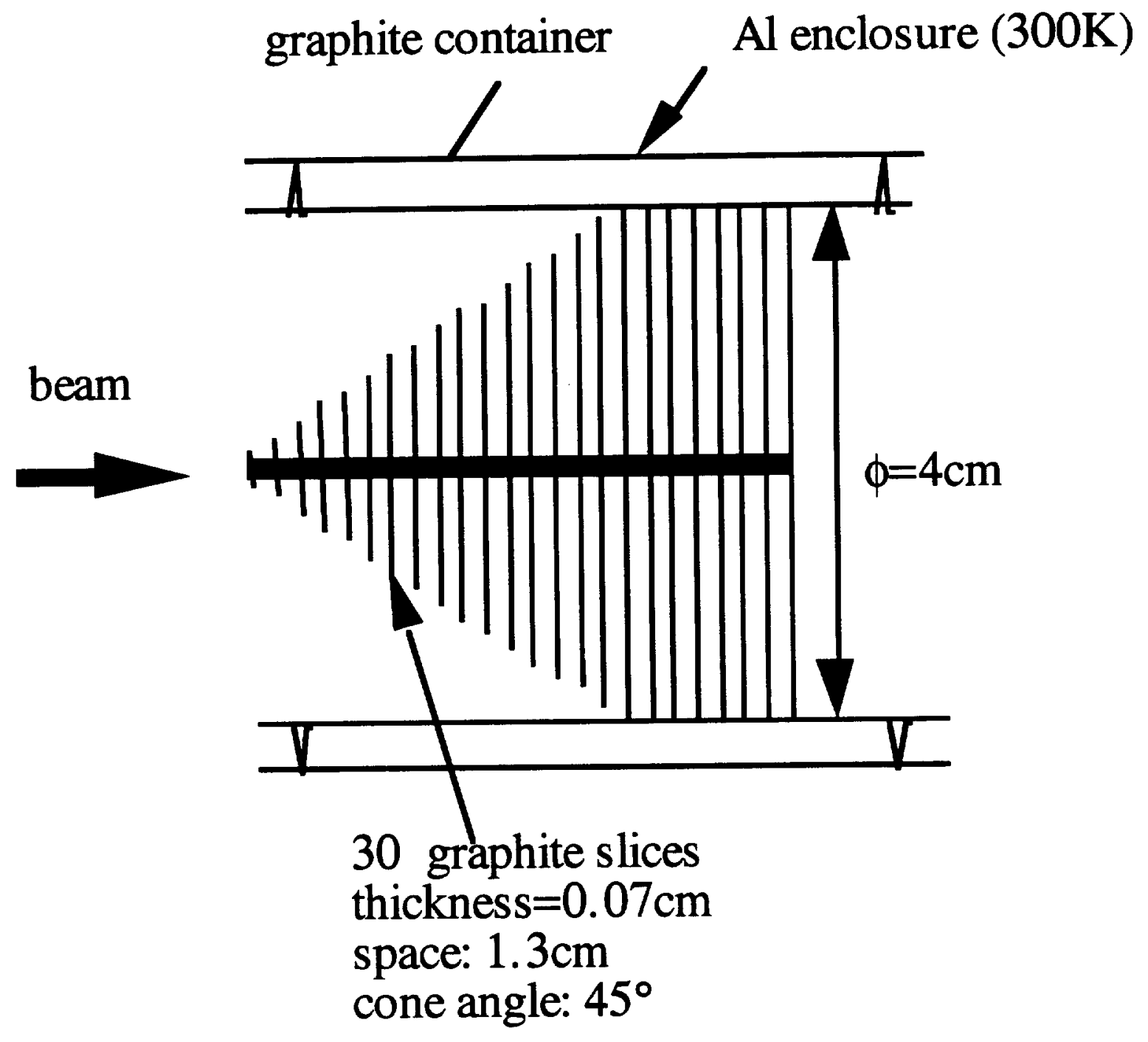

Figure 1 


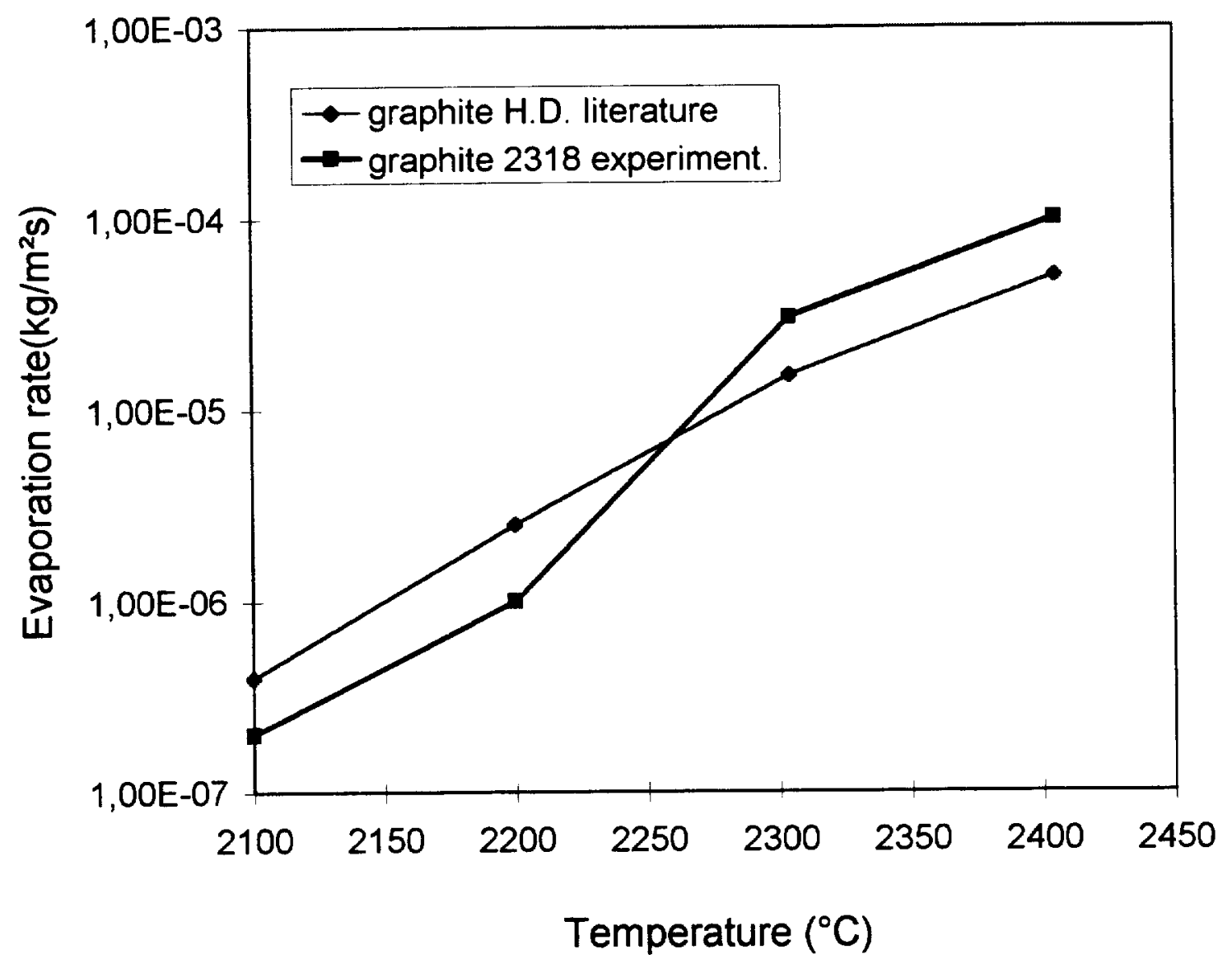

Figure 2 


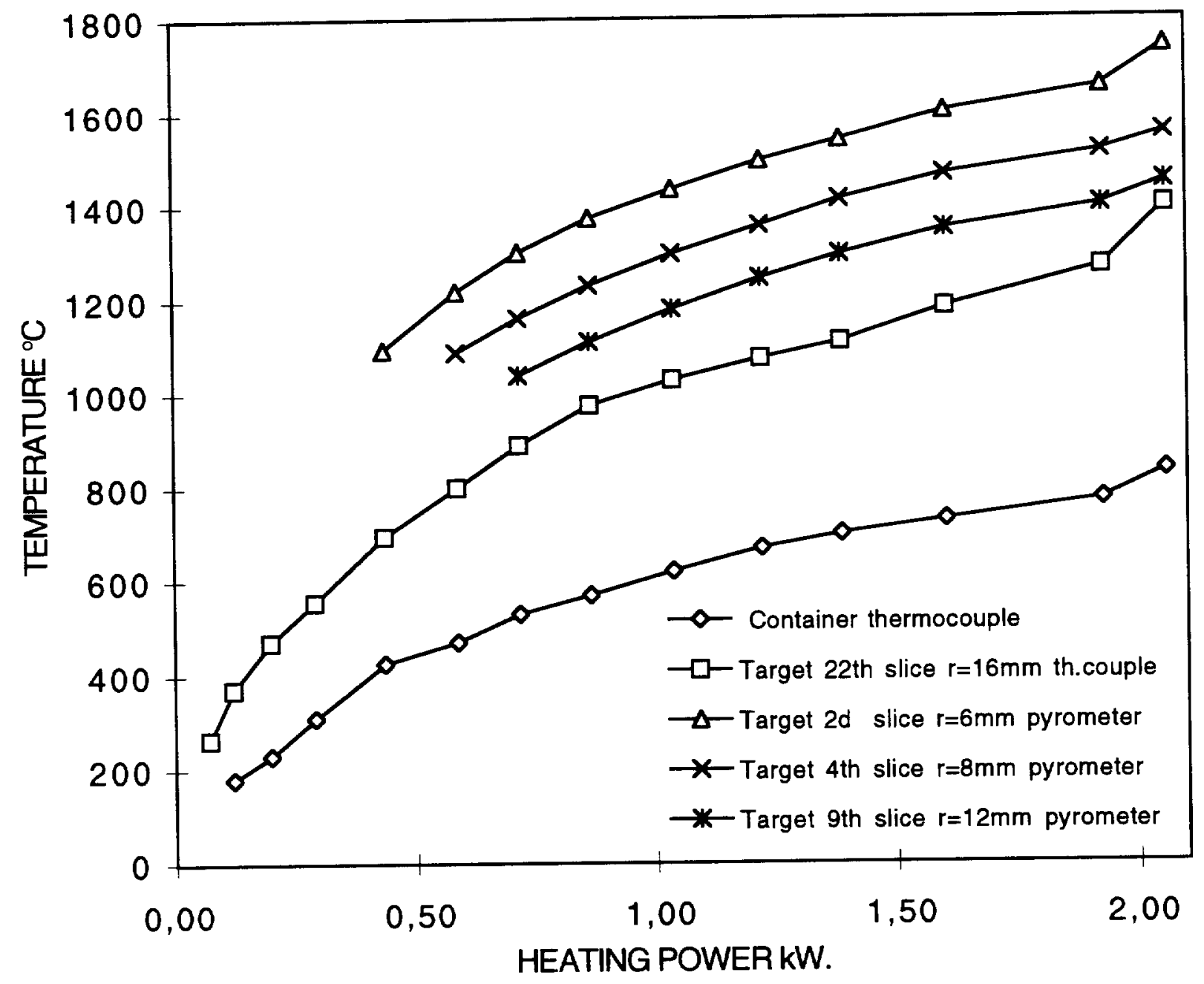

Figure 3 


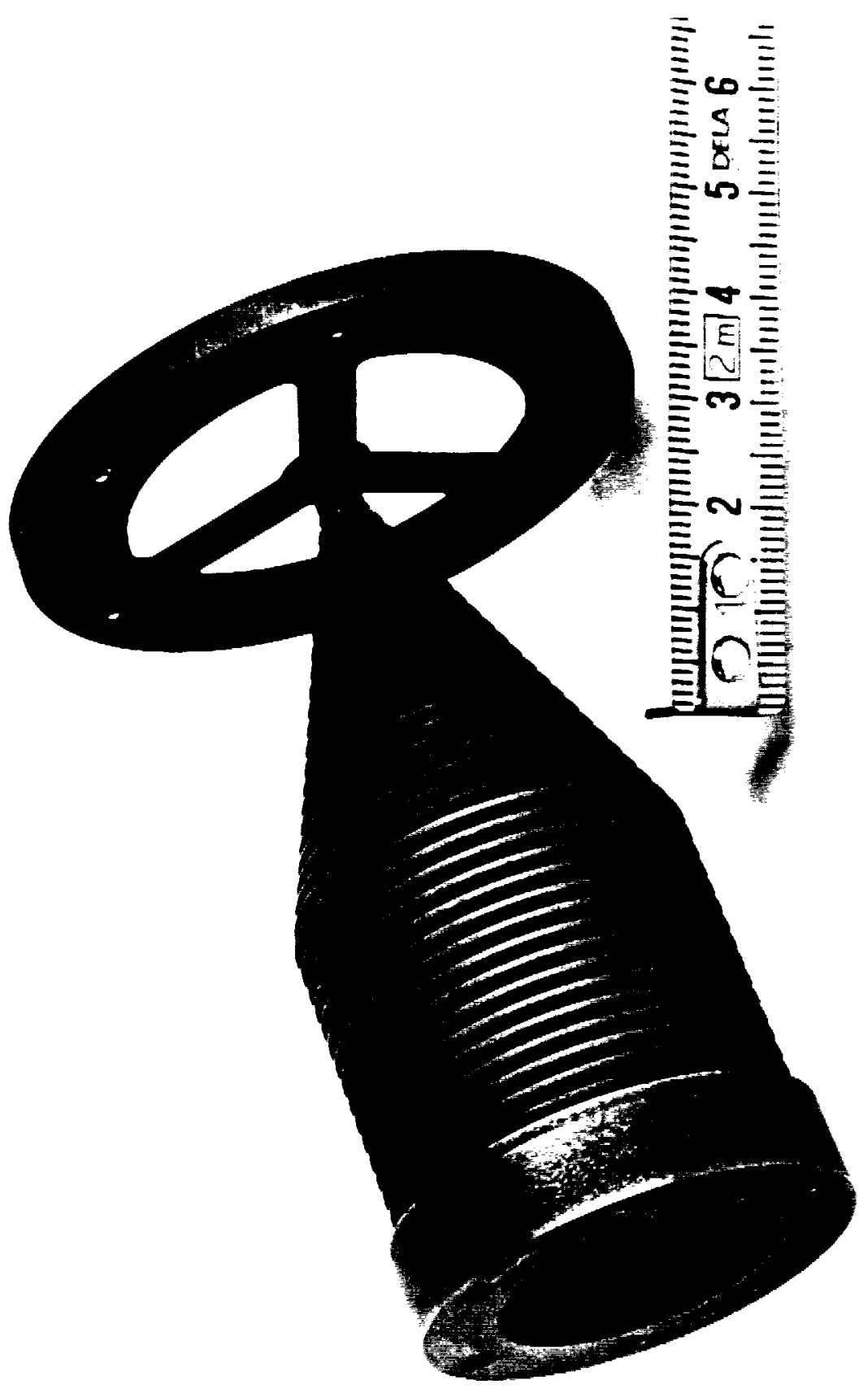

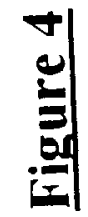




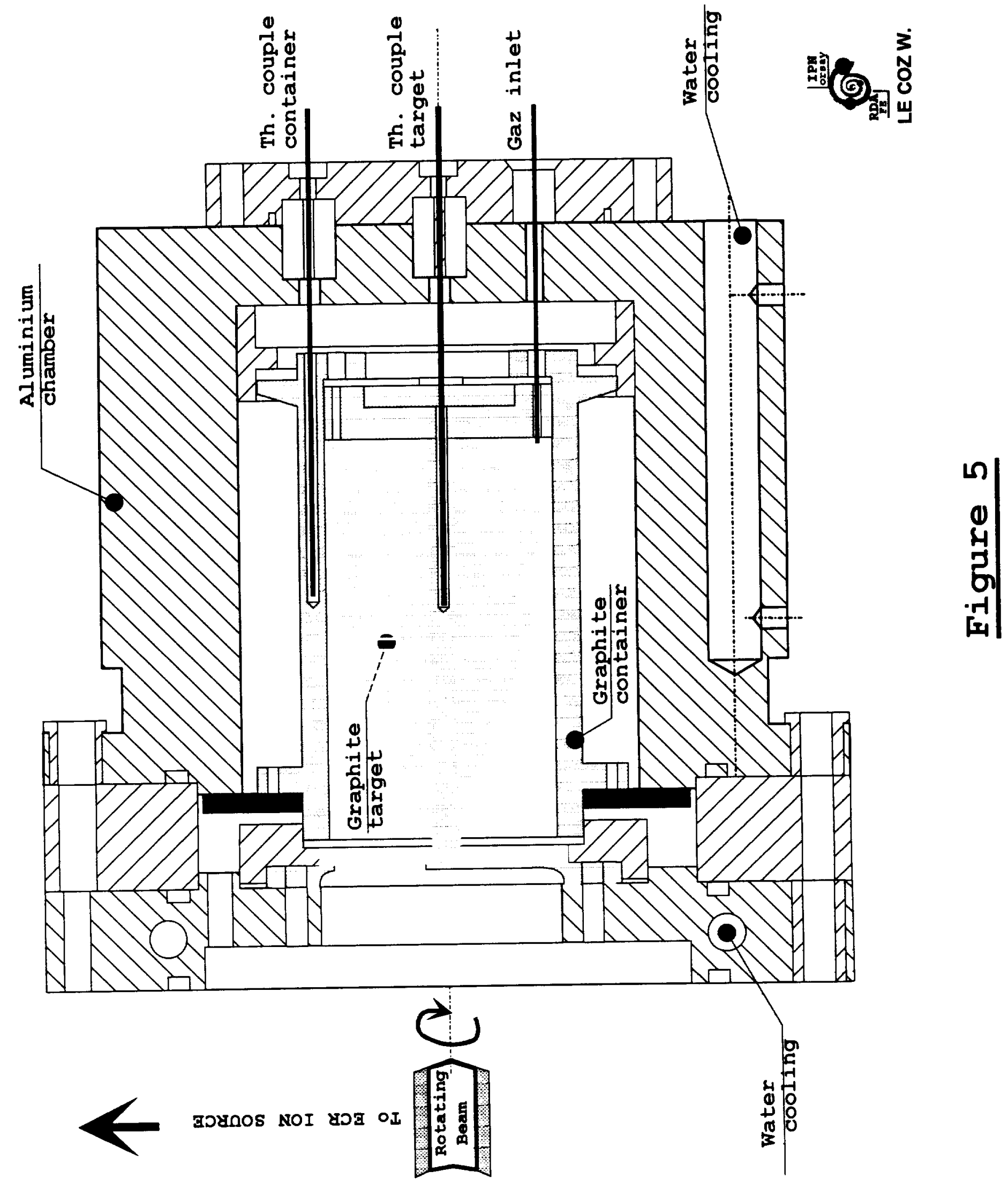

